\title{
Monitoramento de atividade de $\alpha$-amilase com multímetro digital comercial
}

Monitoring of a-amylase activity with commercial digital multimeter

\author{
George Augusto Veloso de Oliveira ${ }^{1 *}$, José Maurício Shennedorf Ferreira da Silva \\ ${ }^{1}$ Universidade Federal de Alfenas \\ *george.unifal@gmail.com
}

\section{Resumo}

O trabalho visa apresentar a possibilidade do uso de um multímetro digital simples para o monitoramento quantitativo da atividade enzimática da $\alpha$-amilase, bem como sua aplicação em laboratório de aulas práticas no ensino superior ou na educação básica. Como ações decorrentes imediatas, apresenta 1) ineditismo e potencial para aplicação de método quantitativo para o ensino de cinética enzimática em aulas de Bioquímica, 2) aplicação em aulas práticas com mínimos recursos e reagentes encontrados em comércio local, e a 3) facilitação do aprendizado de conceitos e análise de dados em cinética enzimática. Adicionalmente, o sistema eletroquímico selecionado permite um acompanhamento simultâneo por meio do desaparecimento da cor da célula anódica e diminuição do sinal elétrico registrado pelo multímetro.

Palavras-chave: Cinética enzimática; atividade enzimática; célula eletroquímica.

\begin{abstract}
This work presents the construction of a potentiometric system for simple monitoring of enzymatic activity of $\alpha$-amylase using a common multimeter together with its application in laboratory classes (higher education or basic education). The results presented here point to 1) novelty and potential method for applying a quantitative teaching about enzymatic kinetics in Biochemistry classes, 2) practical classes with minimal resources and reagents found in local commerce, as well as 3) an assistance for concepts learning and data analysis in enzymatic kinetics. In the experiment, a coherent electrochemical system related to the enzymatic kinetics of $\alpha$-amylase was followed both by the disappearance of the color of the anodic cell as well as a reduction of the electrical signal registered by the instrument.
\end{abstract}

Keywords: Enzymatic kinetics; enzymatic activity; electrochemical cell. 


\section{Ficha da atividade}

\begin{tabular}{|c|c|}
\hline Título & Monitoramento de atividade enzimática com multímetro. \\
\hline Categoria: & Prática de Ensino \\
\hline Tipo & Aula Prática \\
\hline Público-alvo: & $\begin{array}{l}\text { Estudantes de Ensino Médio e Superior (Graduação em diversas } \\
\text { subáreas de Ciências Biológicas, Ciências Agrárias, Ciências Exatas e da } \\
\text { Terra, Engenharias (II, III e IV), Ciências da Saúde, Ciências Agrárias, e } \\
\text { Multidisciplinar). }\end{array}$ \\
\hline $\begin{array}{l}\text { Conteúdos } \\
\text { abordados }\end{array}$ & $\begin{array}{l}\text { Atividade enzimática, cinética enzimática, inibição e modulação } \\
\text { enzimática. }\end{array}$ \\
\hline $\begin{array}{l}\text { Objetivos } \\
\text { educacionais }\end{array}$ & $\begin{array}{l}\text { Realização do experimento em aulas práticas com mínimos recursos e } \\
\text { reagentes encontrados em comércio local; Método quantitativo para o } \\
\text { ensino de cinética enzimática; Auxílio ao aprendiz na compreensão de } \\
\text { conceitos envolvidos em cinética enzimática. }\end{array}$ \\
\hline Duração & 60 minutos. \\
\hline $\begin{array}{l}\text { Materiais } \\
\text { utilizados }\end{array}$ & $\begin{array}{l}2 \text { eletrodos de grafite; } 1 \text { ponte salina de } \mathrm{KCl} \text { ou } \mathrm{NaCl} \text { saturado }(3,0 \mathrm{M}) ; 2 \\
\text { béqueres de } 50 \mathrm{~mL} \text {; Multímetro; Solução de Lugol } 0,5 \% \text {; Tampão Fosfato } \\
\text { pH } 7,0 \text { (ou solução salina em substituição); Solução de amido } 1 \% \text {; Saliva } \\
\text { diluída (1 mL) em Tampão Fosfato 1/1; Solução ácido ascórbico } 1 \mathrm{mg} / \mathrm{mL} \text {; } \\
1 \text { Pipeta Pasteur. }\end{array}$ \\
\hline Criação & $26 / 03 / 2018$ \\
\hline Aplicação & 02/05/2018 \\
\hline Link & $\begin{array}{l}\text { https://drive.google.com/file/d/ } \\
\text { 1ZBtIHVQHk171sMAC_3Q58VX8mSKSvL8c/view?usp=sharing } \\
\text { https://docs.google.com/presentation/d/17-UD-1I- } \\
\text { HOS6nDgad7DDFj_Big3slbY9o1MrNodQxz8/edit?usp=sharing }\end{array}$ \\
\hline
\end{tabular}




\section{Introdução}

Atualmente, observa-se mudanças significativas no processo de ensinoaprendizagem fomentadas pela busca por abordagens metodológicas mais atrativas para o estudante. Somente o uso de aulas expositivas no ensino de Ciências distancia o aluno do gosto pela Ciência e pela descoberta [1].

Assim, na medida em que se consegue realizar um trabalho educativo que proporcione a aprendizagem por descoberta, direciona-se 0 aprendiz a uma aprendizagem significativa [2].

Neste sentido, atividades prático-teóricas contribuem para a construção do conhecimento no processo de aprendizagem. Nas aulas práticas pode-se oportunizar aos estudantes o planejamento, realização e interpretação de resultados obtidos com embasamento científico [3]. Entretanto, muitos experimentos bioquímicos tradicionais concentram-se na aquisição de habilidades manuais em laboratório e no aprendizado de técnicas específicas, levando o aluno à frustração e a falta de interesse com o conteúdo abordado $[1,4]$.

Em breve panorama das atividades práticas utilizadas para o ensino de Bioquímica em aulas de graduação, verifica-se uma amplitude de técnicas diversas para detecção de carboidratos, enzimas, lipídios (saponificação), pH e tampão, e extração de DNA, entre outras. No entanto, nota-se carência de temas igualmente significativos, como o de cinética enzimática, principalmente no tange a seu monitoramento e análises quantitativas. Usualmente, atividades práticas dessa natureza são abordadas sobre a égide qualitativa, como alteração de coloração em tubo de ensaio, por ex.

O ensino de Bioquímica na educação básica é realizado de forma fragmentada, uma vez que não há disciplina específica para o tema. Os fenômenos bioquímicos são expostos aos alunos, desde as aulas de ciências do ensino fundamental, até as aulas do ensino médio [5]. Os experimentos bioquímicos podem auxiliar na compreensão de conteúdo das disciplinas de Química e Biologia que envolvam temas como carboidratos, lipídeos, proteínas e aminoácidos, enzimas, velocidade de reação, célula eletroquímica e metabolismo celular.

Sendo assim, este trabalho propõe a construção de um sistema eletroquímico potenciométrico fundamentado no uso de um multímetro comercial digital, facilmente encontrado em lojas de construção, eletricidade ou mesmo de artigos de baixo custo, estabelecimentos presentes na virtualidade de municípios e distritos da federação. Como alvo principal, o emprego de um multímetro comum para a determinação de atividade 
enzimática da a-amilase, bem como a elaboração de um protocolo para aplicação do método em laboratório de aulas práticas para o ensino de ciências e/ou bioquímica em aulas da educação básica ou de graduação. O protocolo para a atividade prática contempla o monitoramento em tempo real da atividade enzimática da $\alpha$-amilase utilizando-se materiais e reagentes de baixo custo, fácil aquisição e estrita segurança em relação ao manuseio pelos alunos.

\section{Desenvolvimento}

Técnicas eletroquímicas são eficientes no fornecimento de informações sobre sistemas que envolvam cinética de reações com transferência de carga e de reações químicas acopladas [6]. Neste trabalho, a atividade enzimática da $\alpha$-amilase foi monitorada pela transferência de carga que ocorre durante a reação catalítica de degradação do amido em uma célula eletroquímica conforme apresentado na Figura 1.

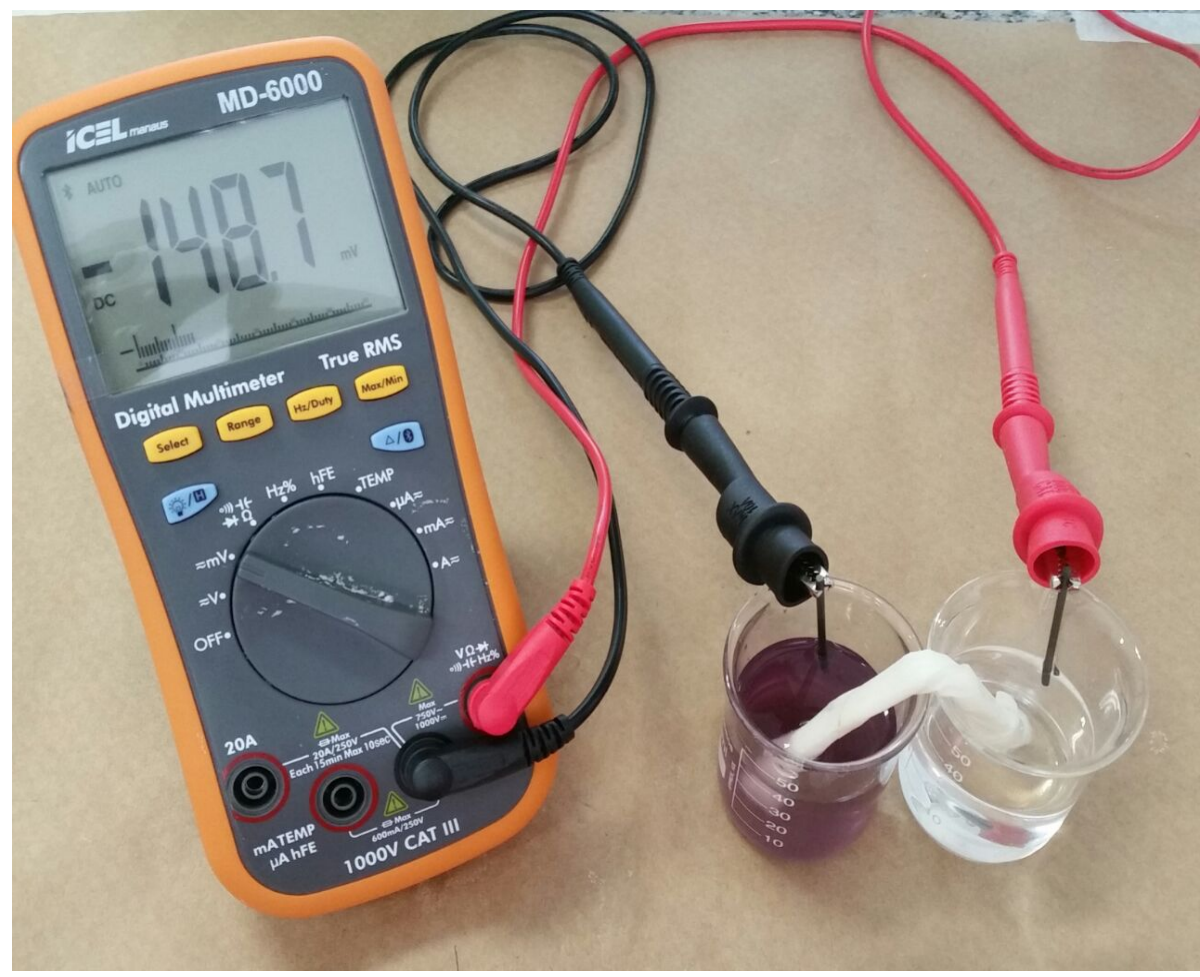

Figura 1. Célula eletroquímica montada para reação catalítica de degradação de amido solúvel por $\alpha$-amilase.

Uma célula eletroquímica consiste de dois condutores elétricos denominados eletrodos, mergulhados em uma solução de eletrólitos selecionados de forma adequada [7]. 


\subsection{Descrição da célula eletroquímica}

Apresenta-se na Figura 2 como a célula eletroquímica foi construída, sendo constituída por uma câmara anódica e uma câmara catódica de volume aproximado a 50 $\mathrm{mL}$, interligadas por uma ponte salina. Para possibilitar a transferência de elétrons, utilizou-se como eletrodos mina de grafite de lapiseira com diâmetro de $2 \mathrm{~mm}$ conectadas ao multímetro.

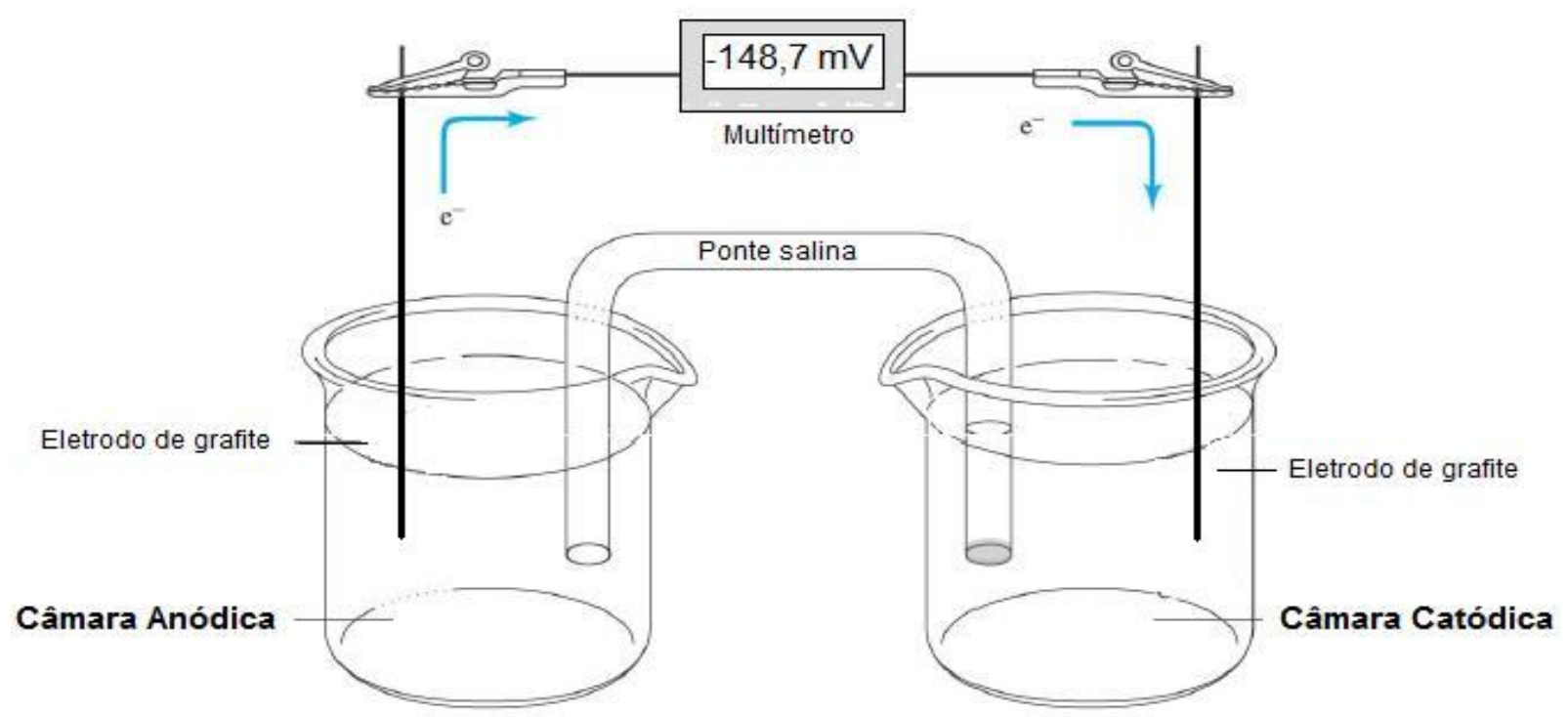

Figura 2. Esquema de montagem da célula eletroquímica empregada no monitoramento potenciométrico de $\alpha$-amilase.

Para que uma corrente comece a fluir na célula é necessário 1) que os eletrodos estejam conectados externamente, através de um condutor metálico, 2) que as duas soluções de eletrólitos estejam em contato, permitindo o movimento de íons entre elas, e 3) que uma reação de transferência de elétrons possa ocorrer em cada um dos eletrodos.

\subsection{Soluções de trabalho}

$\mathrm{Na}$ câmara anódica foram adicionados $30 \mathrm{~mL}$ de solução tampão de fosfato de sódio $\mathrm{pH} 7,0$ na concentração de $100 \mathrm{mM}, 4 \mathrm{~mL}$ de solução de amido $0,5 \%, 1 \mathrm{~mL}$ de solução de ácido ascórbico na concentração de $1 \mathrm{mg} / \mathrm{mL}$ e $2 \mathrm{~mL}$ de solução de lugol 1\%. Após a conclusão desta etapa, homogeneizou-se o sistema.

Para a câmara catódica, foi adicionado $40 \mathrm{~mL}$ do tampão de fosfato de sódio acima. Esta solução tampão é necessária para que haja a condução de corrente elétrica pelo sistema.

A ponte salina foi construída com auxílio de um algodão torcido revestido com fita 
adesiva, e posteriormente embebido em solução de cloreto de sódio saturado. Para verificar o equilíbrio do sistema, registrou-se o valor de potencial informado no multímetro por um período de 10 min até a estabilização do sinal potenciométrico. Adicionou-se $3 \mathrm{~mL}$ de uma solução de saliva/tampão 1:1 na câmara anódica, seguido de homogeneização com auxílio de um bastão de vidro. A seguir, monitorou-se o sinal potenciométrico a cada 20 segundos, durante $10 \mathrm{~min}$. Ao final do experimento, solicitou-se aos alunos a determinação dos parâmetros cinéticos em tratamento matemático aos dados quantitativos obtidos.

\section{Procedimento de uso do material ou aplicação da atividade}

Inicialmente, o estudo foi desenvolvido para a utilização em aulas práticas de graduação da disciplina de Bioquímica, uma vez que aborda o conceito central sobre cinética enzimática. Como um todo, o experimento permitiu ao aluno a realização e interpretação de um sistema eletroquímico, bem como sua relação à cinética enzimática da $\alpha$-amilase acompanhada simultaneamente por meio do desaparecimento da cor da célula anódica e a diminuição do sinal elétrico registrado pelo multímetro.

O fato de constituir-se em uma prática que utiliza materiais de baixo custo e de fácil aquisição (amido, saliva, grafite comum, tintura de iodo, vitamina C) amplia sua forma ou proposta de utilização para a educação básica. Em alguns relatos, tal etapa da educação é carente de aulas práticas devido à ausência de laboratórios, reagentes, materiais diversos, e equipamentos [8].

\section{Procedimentos de avaliação}

Buscando avaliar a viabilidade prática e a capacidade de auxílio da atividade desenvolvida na compreensão do conteúdo de cinética enzimática pelos alunos, após a realização da metodologia descrita, os alunos da disciplina de Bioquímica I do $2^{\circ}$ período de Biotecnologia de 2018 responderam ao questionário apresentado no Quadro 1.

\section{Potencial educacional}

O registro em tempo real, tanto qualitativo, pelo desaparecimento progressivo da coloração azul na câmara anódica, bem como quantitativo, pela aquisição de valores do potencial elétrico durante a catálise devidamente acompanhada pelo multímetro, 
permitem associar os aspectos teóricos-práticos da atividade em si.

\section{Diferencial com as atividades/materiais preexistentes}

A proposta consolidou uma nova atividade prática para o ensino Superior e educação Básica, baseada no monitoramento em tempo real de uma atividade enzimática pelo uso de um multímetro comercial simples como instrumento de medida. Normalmente atividades de enzimas são monitoradas qualitativamente mesmo no Ensino Superior; como exemplos, degradação de gelatina com amaciante de carne (papaína) ou extrato de abacaxi (bromelina), ou mesmo o desaparecimento de coloração característica da interação de triiodina com amido solúvel na presença de amilase.

A atividade prática apresentada também pode ser expandida para obtenção de dados cinéticos da enzima na presença de inibidores, na variação de temperatura e na variação de $\mathrm{pH}$, agregando valor aos conteúdos de estabilidade enzimática, eficiência catalítica, termodinâmica de reações, entre outros.

\section{Resultados da avaliação}

Durante a atividade prática realizada no Laboratório de Bioquímica com os alunos da disciplina de Bioquímica I do $2^{\circ}$ período de Biotecnologia de 2018 da UNIFAL-MG, verificou-se como pontos de destaque:

a) Um sistema eletroquímico coerente em relação à cinética enzimática da a-amilase acompanhada por meio do desaparecimento da cor da célula anódica e diminuição do sinal elétrico registrado pelo multímetro (Figura 3). 

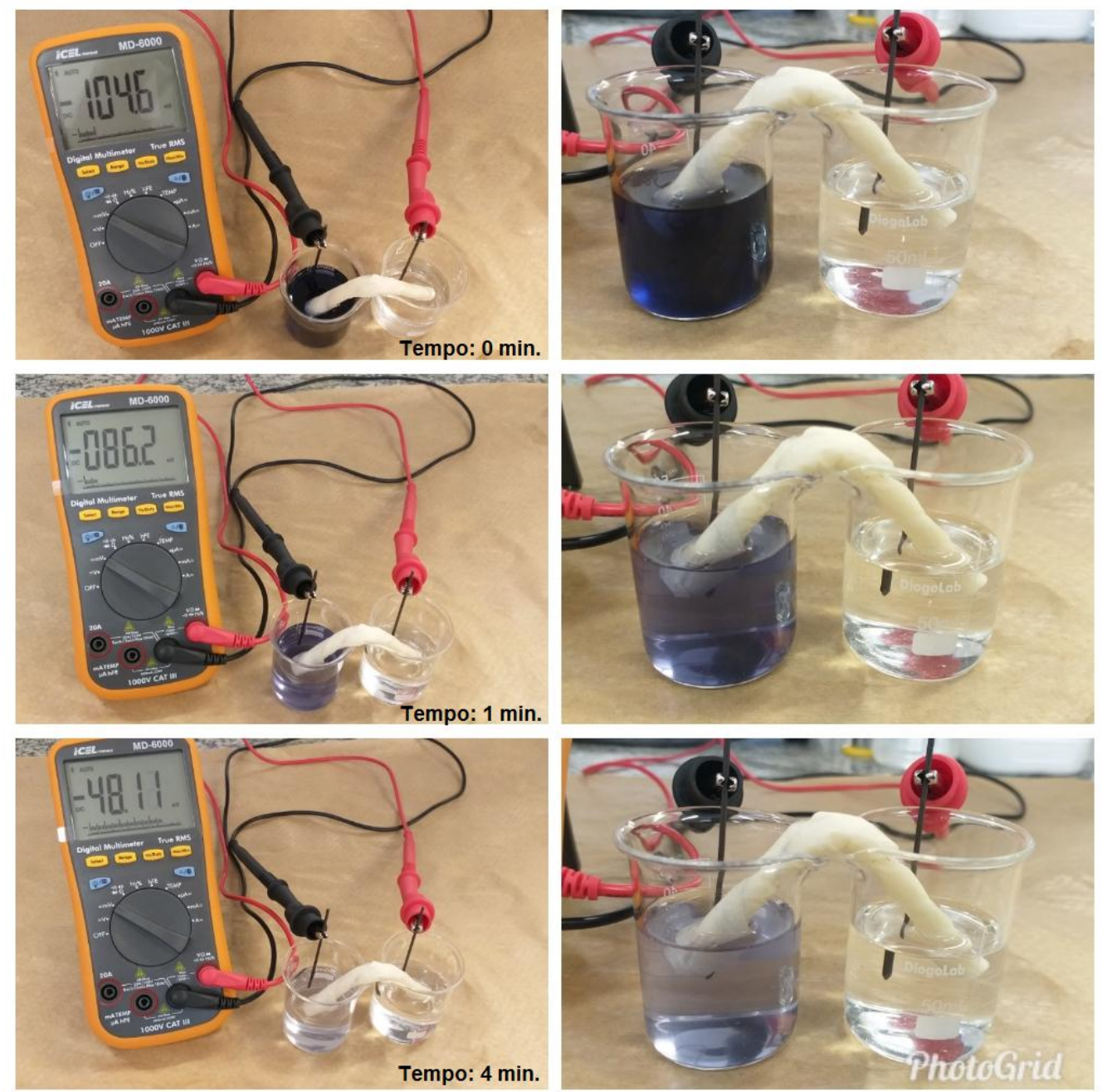

Figura 3. Fotos do experimento de atividade enzimática nos tempos de 0,1 e 4 minutos.

b) Possibilidade de obtenção de parâmetros cinéticos em tratamento matemático aos dados quantitativos obtidos (Figura 4). Dessa forma, Vm e Km aparentes podem ser obtidos por ajuste não linear ou por linearizações clássicas de modelos cinéticos (ex: Lineweaver-Burk, Eadie-Hofstee, entre outros [9]) após tratamento adequado dos dados da curva progressiva [10]. 


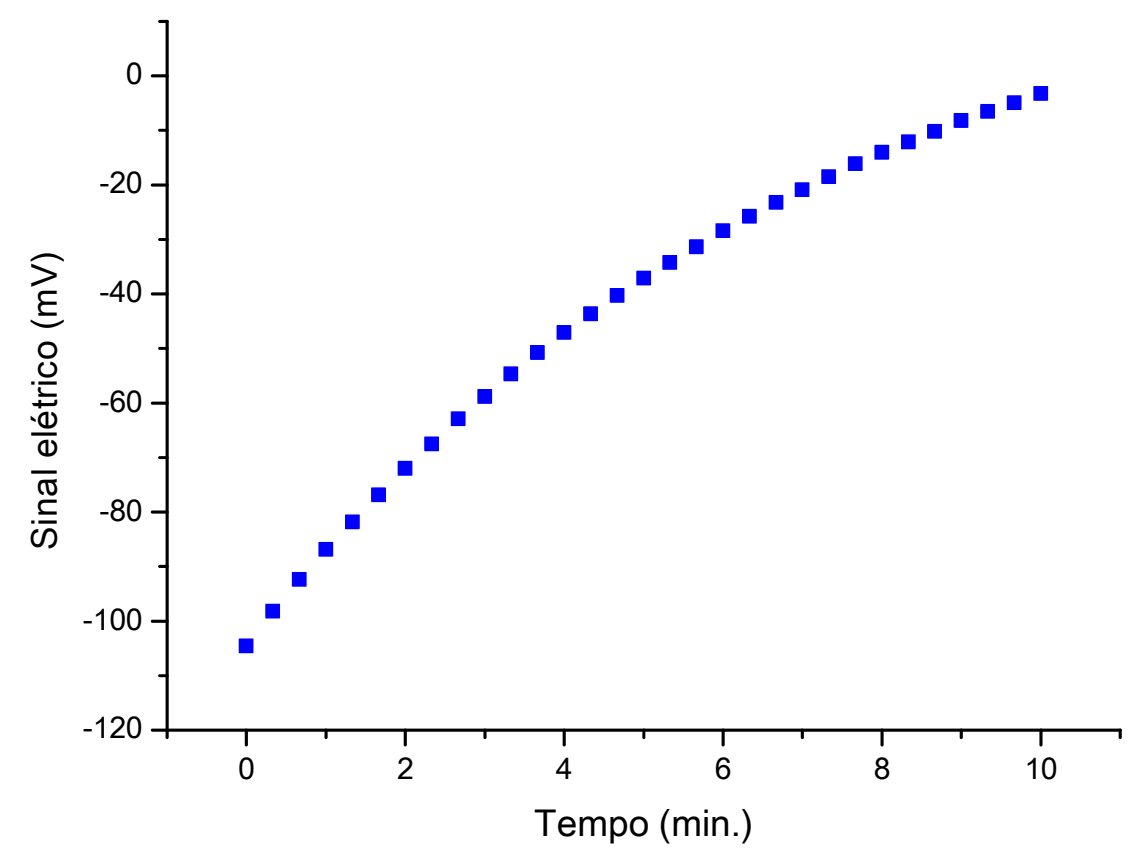

Figura 4. Exemplo de dados quantitativos obtidos na aula prática.

a) A avaliação da viabilidade prática da técnica realizada pelos alunos da disciplina de Bioquímica, tal como mencionado acima, indicou que os estudantes consideraram o experimento de fácil construção e compreensão. Quanto a assimilação do conteúdo, os resultados indicaram que o experimento prático auxiliou na compreensão dos conceitos sobre cinética enzimática.

\section{Considerações finais}

A atividade prática proposta como metodologia de ensino apresentou-se bastante viável para utilização em aulas práticas que envolvam o tema de atividade e/ou cinética enzimática, tanto no ensino superior como na educação básica, nessa com as devidas adequações metodológicas. 


\section{Referências}

[1] Oenning Vanessa, De Oliveira JMP. Dinâmicas em sala de aula: envolvendo os alunos no processo de ensino, exemplo com os mecanismos de transporte da membrana plasmática. Rev. de Ens. de Bioquímica, 2011; 9(1):18-29.

[2] Teixeira RLP, Shitsuka R, Silva PCD. Estudo de caso: Utilização de metodologias ativas em práticas de ciência da corrosão. Anais do XLIV Congresso Brasileiro de Educação em Engenharia (COBENGE 2016). Brasília: ABENGE; 2016 v.1.

[3] Hornink, GG. "ProtVirt: simulação da dosagem de proteínas por espectrometria auxiliando as aulas práticas de Bioquímica. Rev. de Ens. de Bioquímica, 2016; 14(1):130-141.

[4] Astrof, NS, Horowitz G. Protein Colorimetry Experiments That Incorporate Intentional Discrepancies and Historical Narratives. J. Chem. Educ., 2018; 95(7),1198-1204

[5] Gomes LMJ, Messeder JC. Revista Digital como Recurso Tecnológico para o Ensino de Bioquímica na Educação Básica. Revista Virtual de Química, 2015; 7(3): 950-961.

[6] Alencar MAS, Benedetti AV, Fugivara CS, Messaddeq Y. Construção de célula eletroquímica para observação de amostras in situ em estereomicroscópio. Química Nova, 2010; 33(6):1394-1397.

[7] Brun N, Flexer V. Functional Electrodes for Enzymatic and Microbial Electrochemical Systems. London: World Scientific Publishing Europe Limited; 2018.

[8] Moreira LM. O uso do corpo como ferramenta pedagógica: um modelo alternativo que desconsidera a ausência de recursos específicos para o ensino de bioquímica e biologia molecular no ensino fundamental. Revista Brasileira de Ensino de bioquímica e biologia molecular, 5(1):1-14.

[9] Bisswanger H. Enzyme kinetics: principles and methods. [S.I.]: John Wiley \& Sons, 2008.

[10] Marangoni AG. Enzyme kinetics: a modern approach. [S.I.]: John Wiley \& Sons; 2003. 